\title{
High Anxiety Attachment in Eating Disorders: Intergenerational Transmission by Mothers and Fathers
}

\author{
Grazia Attili ${ }^{1}$ \\ Sapienza Rome University, \\ Rome, Italy \\ Lorenza Di Pentima \\ Sapienza Rome University, \\ Rome, Italy
}

\author{
Alessandro Toni \\ Sapienza Rome University, \\ Rome, Italy \\ Antonio Roazzi \\ Universidade Federal de Pernambuco, \\ Recife-PE, Brazil
}

\begin{abstract}
Research on eating disorders (ED) has shown in patients a prevalence of insecure attachment working models (IWMs). Nevertheless, the issue of a prevalence, in patients, of high anxiety IWMs (HAIWMs) has rarely been addressed. This study aimed to investigate the prevalence in ED patients of high anxiety IWMs and their transmission by parents. The Separation Anxiety Test was administered to 55 patients with an ED, a control sample $(n=80)$, their mothers and fathers. The two groups differed significantly, with a prevalence of HAIWMs in the patients and their parents compared to the controls; in ED no significant difference appeared in mother-patient versus father-patient matching for HAIWMs. The implication is that patients with an ED might benefit more from individual attachment-based therapy and/or a family therapy than from other types of psychotherapeutic approaches.
\end{abstract}

Keywords: eating disorders, attachment behavior, anxiety

\section{Apego de Alta Ansiedade em Transtornos Alimentares: Transmissão Intergeracional por Mães e Pais}

\begin{abstract}
Resumo: A pesquisa sobre transtornos alimentares (TA) tem demonstrado em pacientes um predomínio de modelos operacionais internos (MOI) inseguros. No entanto, a questão da prevalência de MOI de alta ansiedade (MOIAA) em pacientes raramente tem sido investigada. Este estudo teve como objetivo investigar a prevalência em pacientes TA (com distúrbios alimentares) de MOI com alta ansiedade e sua possível transmissão por parte dos pais. O Separation Anxiety Test foi administrado a 55 pacientes com TA, uma amostra de controle $(n=80)$, suas mães e pais. Os dois grupos diferiram significativamente com prevalência de MOIAA nos pacientes e seus pais em comparação com os sujeitos de controle. No grupo TA nenhuma diferença significativa foi encontrada na díade mãepaciente versus pai-paciente similares quanto à MOIAA. A implicação é que os pacientes com TA podem se beneficiar mais por uma terapia individual e/ou familiar baseada no apego do que outros tipos de abordagens psicoterapêuticas.
\end{abstract}

Palavras-chave: distúrbios alimentares, comportamento de apego, ansiedade

\section{Apego de Ansiedad Alta en Trastornos de la Alimentación: La Transmisión Intergeneracional de las Madres y los Padres}

\begin{abstract}
Resumen: La investigación sobre los trastornos de la alimentación (TA) ha demostrado en pacientes un predominio de Modelos Operativos Internos (MOI) inseguros. Sin embargo, la cuestión de la prevalencia en pacientes de MOI que se caracteriza por altos niveles de ansiedad (MOIAA) se ha investigado raras veces. Este estudio tuvo como objetivo investigar la prevalencia en pacientes TA (con trastornos alimentarios) de MOI con alta ansiedad y su posible transmisión por parte de los padres. El Separation Anxiety Test de Bowlby se administró a 55 pacientes con un trastorno de la alimentación (TA), una muestra de control ( $n=80)$, sus padres y madres. Los dos grupos difirieron significativamente, con una prevalencia de MOIAA en los pacientes y sus padres, en comparación con los sujetos de control; en el grupo TA, no se encontró ninguna diferencia significativa en la madre-paciente frente a la relación padre-paciente similares con relación a MOIAA. La implicación es que los pacientes con TA pueden beneficiarse más de una terapia individual y/o familiar basado en el apego que otros tipos de enfoques psicoterapéuticos.
\end{abstract}

Palabras clave: trastornos de la ingestión de alimentos, conducta de apego, ansiedad

${ }^{1}$ Correspondence address: Sapienza Rome University. Department of Economical and Social Science. Città Universitaria. Palazzina Ex Tumminelli, Piazzale Aldo Moro 5, 00153, Rome, Italy. E-mail: grazia.attili@uniroma1.it
John Bowlby's theory states that attachment disruption in infancy is a risk factor for psychopathology, in so far as negative early experiences within a family lead to the development of insecure internal working models (IWMs), 
responsible for both maladaptive behaviors and specific emotional patterns in both the short and long-term. Internal working models have been found to tend to be stable over time, although either new affective experiences or major life events may lead individuals to revise them (Pinquart, Feussner, \& Ahnert, 2013).

Family environments of the eating disorder population have often been described, starting with Bruch (1973), as being characterized by overprotection (a caregiving style mostly associated to ambivalent IWMs of individuals), unresponsiveness (a parental style leading to avoidant IWMs) and, more recently, by maltreatment and chaotic styles usually responsible for disorganized IWMs. Thus, unsurprisingly, over the past decade, research dealing with eating disorders (ED) has increasingly provided empirical support for the existence of an association between insecure IWMs and problematic eating behavior. However, results concerning typologies of attachment insecurity appear contradictory, with a high incidence of avoidant, followed by ambivalent IWMs, found in some studies, a prevalence of either ambivalent or disorganized patterns found in others (Gander, Sevecke, \& Buchheim, 2015; Tasca \& Balfour, 2014a), and a prevalence of ambivalent followed by avoidant and disorganized IWMs, with disorganization much more prevalent in patients compared to the control group (Attili, Di Pentima, Toni, \& Roazzi, 2015).

In addition, early in life patients with ED seem to have experienced oversensitivity to being separated from their mother (Sours, 1974). In fact, extreme separation anxiety has been found to be associated with insecure internal working models of the patients (Troisi et al., 2006; Troisi, Massaroni, \& Cuzzolaro, 2005) and, according to Armstrong and Roth (1989), high separation distress, presumably due to disruptions in early attachment relationships, appeared to be directly embodied in the IWMs of $96 \%$ of their eating disordered patients. However, the issue of the prevalence, in this population, not only of insecure IWMs but also of mental states characterized by high levels of separation anxiety, has never been further addressed.

The evidence concerning the association between IWMs and ED sub-types, Restricting Anorexia Nervosa (RAN), Purging Anorexia Nervosa (PAN), Bulimia Nervosa (BN), and Binge Eating Disorder (BED), is also unclear, with some studies finding no differences (Troisi et al., 2005), a prevalence of avoidant patterns in RAN (Attili et al., 2015; Tasca, Ritchie, \& Balfour, 2011), avoidant followed by ambivalent ones in PAN (Attili et al., 2015), ambivalent ones in PAN (Tasca et al., 2011) and either ambivalent or disorganized ones in BED and BN (Attili et al., 2015). Nevertheless, until now the possibility that a high anxiety syndrome might also characterize the different insecure IWMs of ED sub-types has never been investigated.

Almost nothing is known about the distribution of IWMs in the parents of these patients, although one study has shown that anxiety is a feature of mothers and fathers in these groups (Taborelli et al., 2013). However, the extent to which the parents might also present "high anxiety"
IWMs and associations between the IWMs of patients that reveal high separation anxiety and the IWMs of their parents have never been investigated. This is troublesome given the particular importance that the intergenerational transmission of attachment might have within this clinical population (Valdanha, Scorsolini-Comin, Peres, \& Santos, 2013), mainly in cases where parents may also reveal high anxiety IWMs.

The present study was designed to address these points, with the first goal being to analyze the distribution of internal working models (IWMs) in patients with eating disorders, specifically taking into consideration those characterized by high separation distress. The instrument used to assess the IWMs was Klagsbrun and Bowlby's Separation Anxiety Test (SAT) (Klagsbrun \& Bowlby, 1976), which requires respondents to reflect on beliefs and emotions connected to being away from an attachment figure. The hypothesis was that, compared to the control subjects, the patients would reveal a prevalence not only of insecure IWMs but that these would be characterized by intense separation distress, which were termed "high anxiety IWMs (HAIWMs)". The second aim was to assess the distribution of HAIWMs in the parents of the patients and the extent to which a match between the patients with HAIWMs and their mothers and fathers with the same could be detected. This allowed the investigation of both the intergenerational transmission of attachment, a phenomenon well known in the non-clinical population and the verification of the hypothesis that high separation anxiety, presumably due to disruptions in early attachment, might have been a feature of the caregivers of the patients. Given that the IWMs of parents have been found to strongly influence their childrearing styles (Attili, Vermigli, \& Roazzi, 2011), the objective was to contribute to shedding light on the experiences of patients within their families. The hypothesis was that, compared to the control group, a prevalence of HAIWMs would be found in the mothers and fathers of the patients. By also considering the fathers, the aim was to examine the relative impact of each parent in shaping the mental state of an eating disorder patient. The third goal was to study all the questions considering the ED sub-types, thus producing an overall picture of the distribution of HAIWMs in both the patients and their parents. The hypothesis was that, given the clinical observations of a family environment characterized by unresponsiveness and avoidance of overt conflict for the anorexic patients (Valdanha, Scorsolini-Comin, \& Santos, 2013), a prevalence of avoidant HAIWMs would appear in these subjects and in their parents. Furthermore, caregiver styles reported to be based on intrusiveness, overt conflicts, disorganization and confusion in the families of binge eating and bulimic patients (Humphrey, 1986) might present associations with ambivalent HAIWMs in these ED sub-types, mainly with disorganized IWMs in bulimia, given the unresolved traumas that seem to characterize these families. 


\section{Method}

\section{Participants}

A total of 405 participants took part in the study: 55 patients with an ED (mean age 17.8 years, $S D=3.09,50$ female), 80 control subjects (mean age 16.5 years, $S D=0.70$, all female), their respective mothers and fathers recruited from intact families. There are missing data for 3 mothers and 5 fathers within the clinical group and for 1 mother in the control group. The mean age of mothers of the patients was 44.2 years $(S D=6.05)$ and their fathers had a mean age of 48.05 years $(S D=0.50)$. The mean number of years of education of the mothers was 12.8 years $(S D=2.4)$ and 13.1 years $(S D=1.5)$ for the fathers. The mothers of the control group had a mean age of 42.20 years $(S D=0.07)$ and the fathers 46.91 years $(S D=8.48)$. The mean number of years of education of the mothers was reported as 13.1 years $(S D=0.06)$, with 15.05 years $(S D=3.1)$ for the fathers. Participants with eating disorders were recruited from the outpatients attending the Centre for Eating Disorders of two Hospitals in Rome, Italy. Their mean age of onset was 15.3 years $(S D=2.25)$, and the mean duration of the illness was 2.5 years $(S D=1.85)$. Their diagnosis was made by specialist clinicians according to the criteria of the DSM-5, with the following distribution in the sample: Restricting Anorexia Nervosa (RAN) $(n=24)$, Purging Anorexia Nervosa (PAN) $(n=8)$, Bulimia Nervosa $(\mathrm{BN})(n=11)$, Binge Eating Disorder (BED) $(n=12)$. The control subjects were recruited from students attending a high school in Rome, Italy. For both the patients and control subjects, signed terms of consent to participate were obtained from the parents.

\section{Instruments}

The IWMs of attachment were assessed using Attili's Italian version (Attili, 2001) of the Separation Anxiety Test (SAT) of Klagsbrun and Bowlby (1976). The SAT is a semiprojective measure of IWMs based on the assessment of the separation anxiety of an individual, derived directly from attachment theory. It consists of six drawings, each depicting a child whose parents are leaving him/her for a severe (for the evening, leaving the child at home; for the weekend leaving the child with an aunt; for two weeks, leaving the child at home) or mild separation (for the first day at school; in a park, asking him/her to run off and play by him/herself since they want some time alone to talk; putting the child to bed and going out the door). After each picture is described, the tester asks "How does the child in the picture feel?", "Why does he/she feel this way?", "What do you think he/ she will do?", "What is he/she going to feel/do when the parents return". The responses of the participants related to emotions, one for each drawing, are transcribed into response card tables and then classified into 17 emotional categories such as loneliness, sadness, rejection, anger, withdrawal, denial, painful anxiety, happiness, etc. These are grouped into eight main classes of responses linked to the ideas developed by Bowlby (1969, 1973): attachment, loss of self-esteem, hostility, well-being, avoidance/denial, anxiety, confusion, painful anxiety and unresolvable distress.

As in Bowlby's original scoring system, an ordinal scale ranging from -2 to +2 is used and a score is given to responses falling into each class. A score of -2 is assigned to responses referring to unresolvable distress, confusion, avoidance/denial, loss of self-esteem and well-being in severe separation (found to be given mainly by disorganized and avoidant individuals); a score of -1 is assigned to responses such as hostility and attachment- in mild separation (found to be given mainly by ambivalent individuals); a score +2 is awarded to responses such as attachment in severe separation, well-being in mild separation, mainly traced to a secure IWM. By summing these scores, an overall test score allows the classification of subjects into one of the following typologies: secure $(\geq+4)$; insecure ambivalent (a score between +3 and +1 ); insecure avoidant (scores -2 to 0 ); and disorganized (scores -3 and below).

\section{Procedure}

Data collection. For the clinical group (patients and their parents), the SAT was administered to each participant individually in the hospital by two researchers blinded to the diagnosis of the patients. The control group was tested at the homes of the participants. All transcripts were separately classified by two coders blinded to the diagnosis of the patients and trained by the author of the Italian SAT. Regarding agreement between them, Cohen's kappa coefficient was .84 $(p<.001)$.

By using the SAT the assessment was performed of both the IWMs of the participants and the extent to which they revealed high anxiety, that is, chronic separation distress, even though this might have been expressed by different strategies. For this purpose, in line with the procedure by Armstrong and Roth (1989), a measure was used based on the nature of some responses and on the proportion between them and their total. These IWMs were termed "high anxiety IWMs (HAIWMs)". When there were at least 4 out of 6 responses to the SAT related to classes such as attachment in mild separations, loss of self-esteem, hostility and anxiety the IWM of the subject was considered "high anxiety ambivalent"; 4 out of six responses related to well-being in severe separations, loss of self-esteem and avoidance/denial the IWM was classified as "high anxiety avoidant"; 4 out of 6 responses related to attachment in mild separations, loss of self-esteem, irresolvable distress, painful anxiety and confusion the IWM was classified as "high anxiety disorganized". In all these cases, the overall test score was $\leq-3$.

For responses that did not meet the above criterion, the IWMs were termed "low anxiety insecure IWMs (LAIWMs)" The overall test score for these was between +3 and -2 .

Data analysis. The distribution of HAIWMs versus LAIWMs was assessed for the subjects, fathers and mothers separately, in both the patient and control groups; the test of proportion and $\chi^{2}$ were computed for testing differences. Furthermore, in order to analyze whether 
family membership was a bigger factor than individuals in determining HAIWMs, the match was assessed between the IWMs of the adolescents and those of each parent considered separately and of the two parents considered together. The test of proportion for differences was also computed. Finally, aiming to provide a picture of the structure underlying the relationship between the IWMs of attachment and type of ED sub-types, a multidimensional scaling technique such as HOMALS (HOMogeneity analysis by means of Alternating Least Squares) was used (Roazzi et al. 2015).

For the analysis of the data both traditional nonparametric techniques, such as the Kruskal-Wallis test, and correlational analyzes (Pearson and pointbiserial), multiple regression and analysis of variance, as well as a multidimensional statistics technique, such as HOMALS (HOMogeneity analysis by means of Alternating Least Squares) which analyzes the relative homogeneity between categorical variables, were used (Roazzi et al. 2015).

\section{Ethical Considerations}

This research project followed the guidelines of the Research Ethics Code of the AIP (Associazione Italiana di Psicologia - Italian Association of Psychology, 2018, January 15). All the participants were asked to sign the Terms of Consent in duplicate, with one copy remaining with the participant and the other given to the researcher.

\section{Results}

\section{Distribution of Attachment Status for Subjects, Mothers and Fathers}

In Table 1, the distribution of the attachment patterns in the eating disorder and control groups is presented according to subjects, mothers and fathers. A very high percentage of patients, their mothers and fathers presented insecure IWMs ( $n=51-93 \% ; n=47-90 \% ; n=45-90 \%$, respectively). The reverse was the case for the control group, with secure IWMs appearing in $50 \%$ of cases. When "high anxiety" and "low anxiety" IWMs were considered, significant differences in the Test of Proportion were found between the patient group and control group in the distribution of the IWMs, with HAIWMs prevalent in patients. In the control group secure IWMs were prevalent.

Table 1

Distribution of Attachment Patterns in Eating Disorder and Control Groups According to Subjects, Mothers and Fathers

\begin{tabular}{|c|c|c|c|c|}
\hline Groups & Secure & $\begin{array}{c}\text { Insecure } \\
\text { (Low Anxiety) }\end{array}$ & $\begin{array}{c}\text { Insecure } \\
\text { (High Anxiety) }\end{array}$ & Total \\
\hline \multicolumn{5}{|l|}{ Subjects } \\
\hline Patients & $4(7 \%)$ & $22(40 \%)$ & $29(53 \%)$ & $55(100 \%)$ \\
\hline Control & $40(50 \%)$ & $35(44 \%)$ & $5(6 \%)$ & $80(100 \%)$ \\
\hline Total & $44(33 \%)$ & $57(42 \%)$ & $34(25 \%)$ & $135(100 \%)$ \\
\hline Z-score & $-5.20 * *$ & .6672 & $6.11 * *$ & \\
\hline \multicolumn{5}{|l|}{ Mothers } \\
\hline Patients' mothers & $5(10 \%)$ & $35(67 \%)$ & $12(23 \%)$ & $52(100 \%)$ \\
\hline Control mothers & $33(42 \%)$ & $42(53 \%)$ & $4(5 \%)$ & $79(100 \%)$ \\
\hline Total & $38(29 \%)$ & $77(59 \%)$ & $16(12 \%)$ & $131(100 \%)$ \\
\hline Z-score & $-3.97 * *$ & 1.61 & $3.08 * *$ & \\
\hline \multicolumn{5}{|l|}{ Fathers } \\
\hline Patients' fathers & $5(10 \%)$ & $22(44 \%)$ & $23(46 \%)$ & $50(100 \%)$ \\
\hline Control fathers & $35(44 \%)$ & $34(42 \%)$ & $11(14 \%)$ & $80(100 \%)$ \\
\hline Total & $40(31 \%)$ & $56(43 \%)$ & $34(26 \%)$ & $130(100 \%)$ \\
\hline Z-score & $-4.05 * *$ & .17 & $4.07 * *$ & \\
\hline
\end{tabular}

Note. $Z=$ Test of Proportion; ${ }^{*} p<0.05 ; * * p<0.01$.

When, for the patient group, only the insecure IWMs were considered $(n=51)$, HAIWMs tended to appear more than LAIWMs ( $57 \%$ versus $43 \%)(Z=1.39, p=.08)$; whereas, in the control group $(n=40)$ the opposite was significantly the case $(12 \%$ versus $88 \% ; Z=6.71, p<.001)$. The difference between the patients and control subjects was highly significant $\left[\chi^{2}(1)=18.85, p<.001\right]$. In more detail, "high anxiety" avoidant IWMs in the patient group were significantly more prevalent than "high anxiety" ambivalent IWMs $(Z=1.85, p<.05)$.

The IWMs of the mothers significantly differed in the two groups with regard to secure IWMs and HAIWMS. 
Furthermore, within the insecure patterns (patient group mothers: $n=47$; control group mothers $n=46$ ), LAIWMs were more prevalent than HAIWMs in the patient group mothers ( $74 \%$ versus $26 \%, Z=4.74, p<.001)$. Nevertheless, this proportion differed from that of the control group mothers, where $91 \%$ of the IWMs were "low anxiety" and $9 \%$ "high anxiety", with a significance of $Z=7.92, p<.001$, $\left[\chi^{2}(1)\right.$ Yates correction $\left.=3.52, p=.06\right]$.

For the fathers, significant differences were found between the two groups regarding secure IWMs and HAIWMs. Regarding the insecure IWMs (patient group fathers: $n=45$; control group fathers: $n=45$ ), HAIWMs of the patient group fathers were very slightly more prevalent than LAIWMS (51\% versus $49 \%$ ), while in the control group fathers the reverse was significantly the case $(24 \%$ versus $76 \%, Z=4.85, p<.01)$, with the difference between the two groups being significant $\left(\chi^{2}=6.80, p<.01\right)$. The HAIWMs appeared more in the fathers of patients than in their mothers $(Z=2.44, p<.01)$.

\section{Patient-Mother versus Patient-Father and versus Patient- Both Parents Matching}

An analysis was made of the match between the IWMs of the participants and those of their parents, considering both separately and together (Figure 1). In this way, the intergenerational transmission of HAIWMs and LAIWMs and whether one parent was more influential than the other in shaping the IWMs of the child could be investigated. For this analysis, only the subjects for whom data was collected for both mother and father were considered $(n=44$ triads in the clinical group and $n=80$ in the control group).

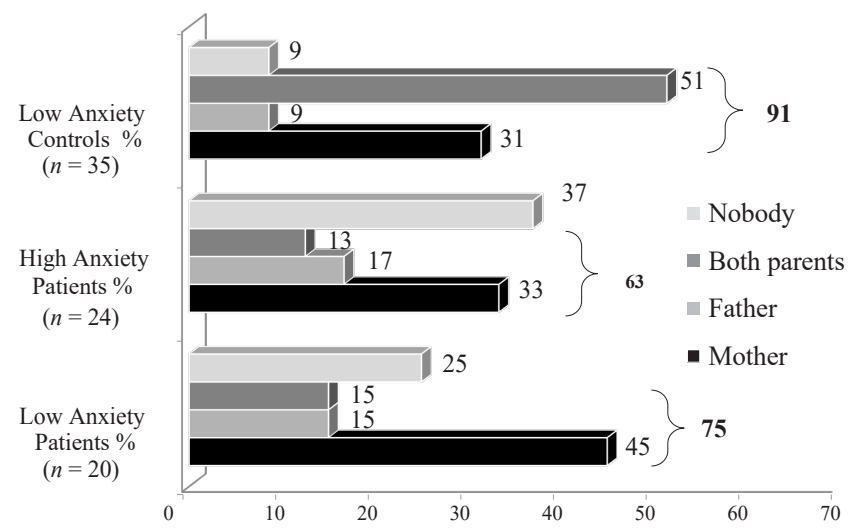

Figure 1. Mother-patient, father-patient and both parentspatient matching for the IWMs of patients and control subjects.

It was found that the HAIWMs of the patients tended to match more those of their mothers than of their fathers and more than those of both parents considered together. The same trend was found for the LAIWMs; in this case the differences were significant $(Z=2.07 ; p<.05 ; Z=2.07$, $p<.05$ respectively). The LAIWMs of the control subjects significantly matched more those of their mothers than of their fathers $(Z=2.39, p<.05)$ and less, although not significantly, than those of both parents considered together. The small number of HAIWMs in the control group $(n=5)$ did not allow any analysis. Interestingly $49 \%$ of the secure IWMs of the control subjects matched those of both parents.

\section{Distribution of HAIWMs versus LAIWMs in Subjects and their Parents for the ED Sub-Types}

Several HOMALS analyses were performed to investigate the eventual clusters of patient and parental HAIWMs and LAIWMs $x$ types of ED diagnoses and $x$ control subjects. For this analysis, all the typologies of insecure patterns (Low/High Anxiety Ambivalent; Low/High Anxiety Avoidant; Disorganized) were considered separately, even though these were in very small numbers. This was done with the aim of providing evidence for the hypothesis that the distribution that had been found in a previous study for associations between IWMs and ED diagnoses (Attili et al., 2015) could be strengthened by associations with the same attachment typologies but at a high level of anxiety. For this, "Space diagrams" were developed, visualizing the relational structure of all the variables studied.

The HOMALS solution for the control group and the ED sub-types of patients can be visualized as having a polar partition (Figure 2). On the bottom right portion of the plot are the control participants close to the variable Secure IWMs and both ambivalent and avoidant LAIWMs. On the upper right portion of the diagram Binge Eating subjects are located close to Ambivalent HAIWMS. On the left upper side Restricting Anorexia Nervosa (RAN) and Purging Anorexia Nervosa (PAN) subjects appear mostly close to the variable "Avoidant HAIWMs"; however, PAN subjects are also located not far from Ambivalent HAIWMs. In the left bottom portion, Disorganized High Anxiety IWMs appear to be prevalent in Bulimia Nervosa (BN) subjects.

The HOMALS solution for the mothers of the control group and for those of the patient group with ED sub-types can be visualized in Figure 3. In the right bottom part of this axial partition the control group mothers are found close to the variable "secure IWMs", although not far from Avoidant and Ambivalent LAIWMs. The mothers of the Binge Eating patients are also located close to these. In the upper part of the diagram, the mothers of patients with Purging Anorexia are located close to Disorganized and Ambivalent HAIWMs. Mothers of patients with Restricting Anorexia and Bulimia are located in the left bottom part of the diagram close to Avoidant HAIWMs.

The HOMALS solution for fathers can be visualized in Figure 4. In the right part of this axial partition, the control group fathers are found close to the secure IWMs variable, although also close to Ambivalent LAIWMs. In the upper part of the diagram, almost all the ED sub-types are located close to HAIWMs, in particular, the fathers of Bulimic patients are close to Disorganized patterns and those of Binge Eating and Restricting AN patients close to Ambivalent HA patterns. Fathers of Purging AN patients are located in the left bottom part, close to Avoidant HAIWMs. 


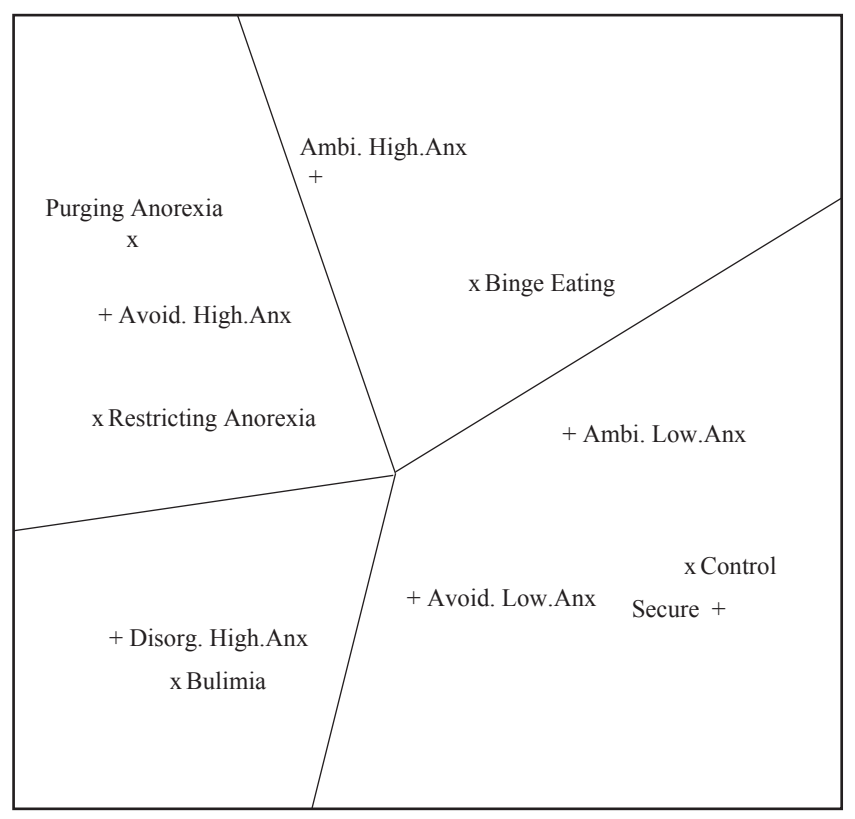

Figure 2. Subject sample (patients and controls): HOMALS solution of Diagnosis (5: Restricting Anorexia / Purging Anorexia / Bulimia / Binge Eating / Control) versus Internal Working Models of Attachment [6: Secure / Ambivalent (Low/High Anxiety) / Avoidant (Low/High Anxiety) / Disorganized (High Anxiety)].

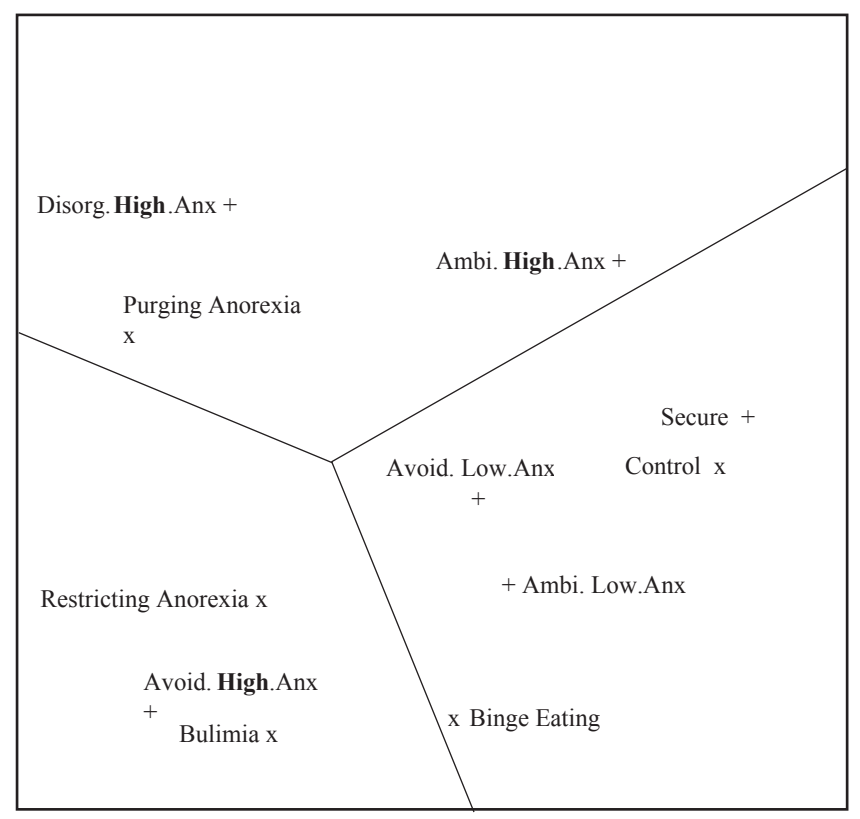

Figure 3. Mother sample (patients and controls): HOMALS solution of Diagnosis (5: Restricting Anorexia / Purging Anorexia / Bulimia / Binge Eating / Control) versus Internal Working Models of Attachment [6: Secure / Ambivalent (Low/High Anxiety) / Avoidant (Low/High Anxiety) / Disorganized (High Anxiety)].

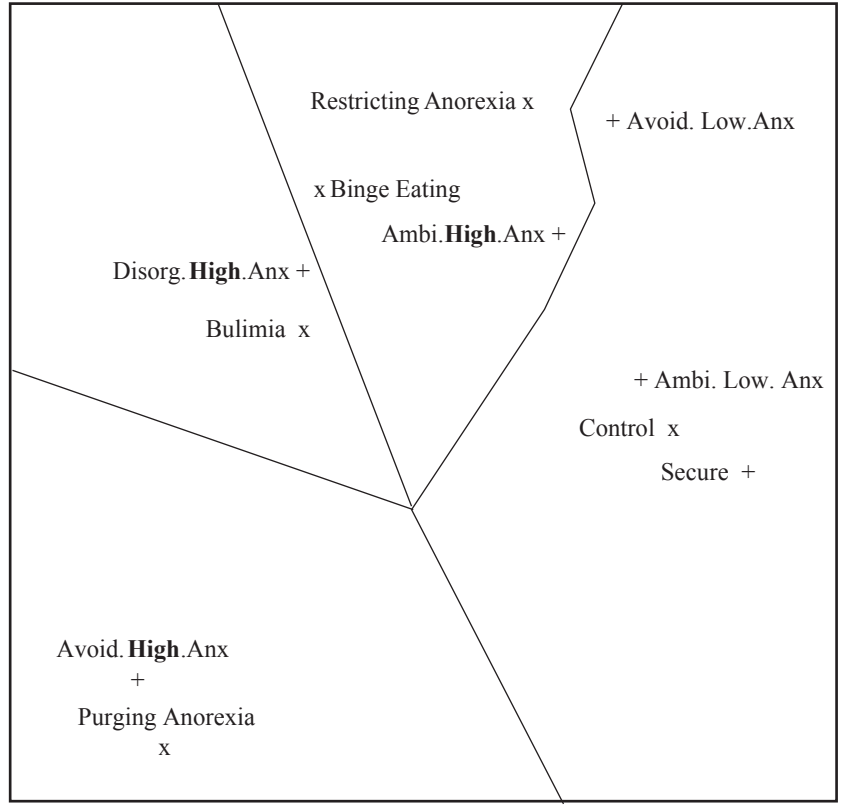

Figure 4. Father sample (patients and controls): HOMALS solution of Diagnosis (5: Restricting Anorexia / Purging Anorexia / Bulimia / Binge Eating / Control) versus Internal Working Models of Attachment [6: Secure / Ambivalent (Low/High Anxiety) / Avoidant (Low/High Anxiety) / Disorganized (High Anxiety)].

\section{Discussion}

By using the Klagsbrun and Bowlby's Separation Anxiety Test (SAT) (Klagsbrun \& Bowlby, 1976) for assessing the internal working models of attachment (an instrument that, to the best of our knowledge, has only been used, in the version by Hansburg (1972), by Armstrong and Roth (1989) for patients) it was consistently found that the IWMs of patients with an ED were, not only mostly insecure, in line with the specialized literature quoted in the introduction, but also presented extreme separation anxiety, in line with the results of Armstrong and Roth (1989). The percentage of "high anxiety" IWMs was significantly higher in the patients than in the control subjects. Furthermore, the patients presented more HAIWMs than insecure LAIWMs (even though just at the limit of significance), with the reverse being significantly the case in the control subjects. It seems possible to argument in favor of the hypothesis that high anxiety IWMs might be considered an expression of a pathological process that culminates in the appearance of eating disorders.

As a whole, these results go beyond those by Troisi and colleagues $(2005,2006)$, and Armstrong and Roth (1989) who found extreme separation anxiety only in their ambivalent ED patients and only in terms of expressed anxiety. Our findings provide evidence of HAIWMs even in avoidant subjects even though their anxiety is expressed through specific maladaptive emotional regulation strategies 
such as the tendency to emphasize positive emotions rather than negative ones. In agreement with the findings of Overton, Selway, Strongman, and Houston (2005), the avoidant subjects investigated in the present study seemed to lack the capacity to hypothesize anger and sorrow in the children depicted in the SAT test illustrations.

By using a HOMALS analysis, a complex structure emerged that sheds light on the attachment styles of the patients according to ED sub-types. The IWMs of the control subjects were mainly either secure or low anxiety, while the ED patients presented mainly HAIWMs, with Ambivalent HAIWMs in the BED patients (even though Ambivalent LAIWMs were also found in the group with this disorder), both avoidance and ambivalence HAIWMs in the PAN patients, Avoidant HAIWMs in the RAN patients, and Disorganized HAIWMs in the BN patients. These results demonstrate associations between ED sub-types and types of attachment characterized by high anxiety, as shown in studies where the IWMs were considered globally (Attili et al., 2015; Tasca et al., 2011).

Considering the parents of the ED patients, all of the insecure attachment patterns, in approximately the same percentages, were found in both mothers and fathers. Nevertheless, the most interesting result is that the "high anxiety" IWMs were found significantly more in both parents of the patients than in those of the control subjects, where by contrast more secure IWMs were found in both mothers and fathers.

Since the IWMs of parents greatly affect their childrearing styles (Attili et al., 2011), these findings underline the extent to which high separation anxiety might characterize caregiving styles in all these families. In fact, in another of our studies we found that parents with HAIWMs were reported by their ED children as less warm and caring and more intrusive, controlling and autonomy reducing than the parents with LAIWMs (Attili, Di Pentima, Toni, \& Roazzi, 2016).

An important contribution of this study refers to the consideration of the complex dynamics characterizing these families where previous studies have found a lack of skills in resolving conflicts and stressful events and an emotional distance between family members (Leonidas \& Santos, 2015). Our findings show that difficulties in the relationships of the patient go beyond the bond solely with the mother and consider the role of the father in the development of eating disorders. At present, no research work has analyzed the direct and concomitant influence of the IWMs of the father in ED populations. In fact, another striking result of this study regards the intergenerational transmission of attachment, not just by mothers, but also by fathers, so far neglected in studies on ED patients. The intergenerational transmission of HAIWMs appeared in $63 \%$ of the patients, and even though the transmission of LAIWMs was found in $75 \%$ of the cases, the evidence that almost no HAIWMs appeared in the control subjects should be highlighted. It also appears that, even though mothers had a slightly greater effect than fathers regarding HAIWMs, the differences were not significant.
By contrast, in the control subjects the reverse was the case, with these families the match between the IWMs of the adolescents and those of both parents presenting a high percentage of secure IWMs.

These results apparently corroborate those of other studies that indicate that it is mainly the relationship with the mother that affects the onset of eating disorders (Moura, Santos, \& Ribeiro, 2015). However, since the difference was not significant and since, according to attachment theory, IWMs are transmitted by the figure that fulfills the main caregiving role, it is possible to argument in favor of the hypothesis that neither the mother nor father seemed to prevail in the care of their child and that the fathers had a role equivalent to that of the mothers in shaping the IWMs of the patients. In addition, by using a projective test, such as the SAT, it was possible to assess directly the extent to which fathers of patients were also unconsciously overwhelmed by chronic separation anxiety distress and since HAIWMs were significantly more prevalent in fathers than in mothers, it can be hypothesized that they contributed a great deal to the HAIWMs of their children.

The HOMALS analysis concerning the parents demonstrates the complex structure characterizing the family experiences of the patients related to the ED subtypes, as opposed to those of the control group. A prevalence of Disorganized HAIWMs was found in the fathers of the Bulimic patients, of Ambivalent HAIWMs in those of BED patients and of Avoidant HAIWMs in those of PAN patients. This means that the HAIWMs found in the above patients might have been transmitted by their fathers, although the Avoidant HAIWMs and Ambivalent HAIWMs of the mothers might explain the HAIWMs of the RAN and PAN patients respectively.

In conclusion, the study findings show that eating disorders may emerge in different family systems that have high separation anxiety in common. Thus, ED patients might feel that they cannot rely on their parents. Disengaging from efforts to gain comfort from their parents and redirecting attention from attachment to goals that are more feasible, such as changing their appearance, might be interpreted as a tactic for getting the attention of their parents. However, it could also be interpreted as an unconscious strategy to avoid confronting the grief of having parents so overwhelmed by their own anxiety that they lack the capacity for protection.

This study has several limits. The most obvious is the small number of patients for each ED sub-type, which does not allow an in depth exploration of the intergenerational transmission of anxious IWMs and does not permit the use of a multilevel modeling approach for the eating disorders to be considered separately. In addition, the problem of relative intra-family effects versus inter-family effects could not be addressed. Another important limit is the cross sectional, rather than longitudinal, design of the study. This does not provide information regarding whether the IWMs of the parents might have affected the parenting style in the past or whether the burden of an eating disorder might have been the cause of the separation anxiety and insecure working models 
of the patients and the parents. However, it is also true that, even though IWMs can change over life, see meta-analyses by Pinquart and colleagues (2013), their revision is usually the consequence of a disruption in attachment relationships and/or of stressful events occurring in the absence of protective figures more than of stress per se. Furthermore, changes take a long time, making it is difficult to hypothesize that a revision of the IWMs of the parents had taken place within the two and a half year mean duration of the illness of the patients. Therefore, it is plausible that the insecure IWMs of the parents were the consequence of their own attachment relationships and the antecedents of the IWMs of their children, in accord with what was found by Attili and colleagues (2016) and Tereno, Soares, Martins, Celani, and Sampaio (2008), regarding the memories of the patients related to parental childrearing behavior.

It is suggested that future studies investigate the role of specific variables that might explain the association between high anxiety attachment and eating pathology and the impact of co-morbid psychiatric disorders, since they appear very regularly in this clinical population (O'Brien \& Vincent, 2003). Furthermore, future studies should examine in depth the relative impact of the mothers and fathers regarding the transmission of separation anxiety in the different ED sub-types.

The results lead to the consideration, in line with suggestions by Tasca (2014), Tasca and Balfour (2014b) and Tasca and colleagues (2011), that ED patients might benefit less from current symptom-focused therapies. In contrast, they may benefit more from therapists that provide nurturing in a non-threatening way, fulfilling the role of a secure base and giving emotional support according either to an individual therapy based on attachment constructs or to a family therapy based on systemic approaches (Souza \& Santos, 2010). The high chronic separation anxiety characterizing all the ED sub-types could necessitate a treatment aimed at helping the patients and their parents to reorganize their anxious emotions, as highlighted by Leonidas and Santos (2014) and Tereno and colleagues (2008) and to revise their internal working models by recalling memories of the contrasting and conflicting way they were treated by their parents and by focusing attention on their own conflicting needs. However, the intervention should take into consideration the specificities of each attachment cognitive script. The avoidant IWMs of Anorexia, for example, might require a non-intrusive intervention, while the ambivalence of Binge Eating and the disorganization of Bulimic patients might necessitate a treatment aimed mainly at their emotional dysregulation.

\section{References}

Armstrong, D. M., \& Roth, J. G. (1989). Attachment and separation difficulties in eating disorders: A preliminary investigation. International Journal of Eating Disorders, 8(2), 141-155. doi:10.1002/1098-108X(198903)8:2<141::AIDEAT2260080203>3.0.CO;2-E
Associazione Italiana di Psicologia - Italian Association of Psychology. (2018, January 15). Ethical Code. Retrieved from http://www.aipass.org/node/11560

Attili, G. (2001). Ansia da separazione e misura dell'attaccamento normale e patologico: Versione modificata e adattamento italiano del Separation Anxiety Test (SAT) di Klagsbrun e Bowlby [Separation anxiety and assessment of both normal and pathological attachment: Modified version and Italian adaptation of the Separation Anxiety Test by Klagsbrun and Bowlby]. Milano, Italia: Unicopli.

Attili, G., Di Pentima, L., Toni, A., \& Roazzi, A. (2015). Attachment styles and eating disorders: The combined effect of mothers' and fathers' mental states. Attachment and Complex Systems, 2(2), 53-66.

Attili, G., Di Pentima, L., Toni, A., \& Roazzi, A. (2016). Trascuratezza emotiva, attaccamento e ansia da separazione nei disturbi alimentari: Uno studio su pazienti adolescenti e sui loro genitori [Emotional neglect, attachment and separation anxiety in eating disorders: A study on adolescents and their parents]. Maltrattamento e Abuso All'Infanzia: Rivista Interdisciplinare, 18(2), 95118. doi:10.3280/MAL2016-002006

Attili, G., Vermigli, P., \& Roazzi, A. (2011). Rearing styles, parents' attachment mental state, and children's social abilities: The link to peer acceptance. Child Development Research, 2011, 1-12. doi:10.1155/2011/267186

Bowlby, J. (1969). Attachment and Loss, Vol.1. Attachment. London: Hogarth Press.

Bowlby, J. (1973). Attachment and Loss, Vol.2. Separation: Anxiety and Anger London: Hogarth Press.

Bruch, H. (1973). Eating disorders: Obesity, anorexia nervosa, and the person within. New York, NY: Basic Books.

Gander, M., Sevecke, K., \& Buchheim, A. (2015). Eating disorders in adolescence: Attachment issues from a developmental perspective. Frontiers in Psychology, 6, 1136. doi:10.3389/fpsyg.2015.01136

Hansburg, H. G. (1972). Adolescent separation anxiety: A method for the study of adolescent separation problems. Springfield, IL: C. C. Thomas.

Humphrey, L. L. (1986). Family relations in bulimicanorexic and nondistressed families. International Journal of Eating Disorders, 5(2), 223-232. doi:10.1002/1098-108X(198602)5:2<223::AIDEAT2260050204>3.0.CO;2-U

Klagsbrun, M., \& Bowlby, J. (1976). Responses to separation from parents: A clinical test for young children. British Journal of Projective Psychology \& Personality Study, 21(2), 7-27.

Leonidas, C., \& Santos, M. A. (2014). Social support networks and eating disorders: An integrative review of the literature. Neuropsychiatric Disease and Treatment, 10, 915-927. doi:10.2147/NDT.S60735 
Leonidas, C., \& Santos, M. A. (2015). Family relations in eating disorders: The Genogram as instrument of assessment. Ciência \& Saúde Coletiva, 20(5), 14351447. doi:10.1590/1413-81232015205.07802014

Moura, F. E. G. A., Santos, M. A., \& Ribeiro, R. P. (2015). A constituição do vínculo mãe-filha e sua relação com os transtornos alimentares. Estudos de Psicologia (Campinas), 32(2), 233-247. doi:10.1590/0103166X2015000200008

O’Brien, K. M., \& Vincent, N. K. (2003). Psychiatric comorbidity in anorexia and bulimia nervosa: Nature, prevalence, and causal relationships. Clinical Psychology Review, 23(1), 57-74. doi:10.1016/S02727358(02)00201-5

Overton, A., Selway, S., Strongman, K., \& Houston, M. (2005). Eating disorders-the regulation of positive as well as negative emotion experience. Journal of Clinical Psychology in Medical Settings, 12(1), 39-56. doi:10.1007/s10880-005-0911-2

Pinquart, M., Feussner, C., \& Ahnert, L. (2013). Metaanalytic evidence for stability in attachments from infancy to early adulthood. Attachment \& Human Development, 15(2), 189-218. doi:10.1080/14616734.2013.746257

Roazzi, A., Souza, B. C., \& Bilsky, W. (2015). Facet Theory: Searching for Structure in Complex Social, Cultural and Psychological Phenomena. Recife: Editora Universitária da UFPE. doi:10.13140/RG.2.1.3267.0801 Retrieved from https://goo.gl/p48ywC

Sours, J.A. (1974). The anorexia nervosa syndrome. International Journal of Psychoanalysis, 55, 567-576

Souza, L. V., \& Santos, M. A. (2010). A participação da família no tratamento dos transtornos alimentares. Psicologia em Estudo, 15(2), 285-294. doi:10.1590/ S1413-73722010000200007

Taborelli, E., Krug, I., Karwautz, A., Wagner, G., Haidvogl, M., Fernandez-Aranda, F., ... Micali, N. (2013). Maternal anxiety, overprotection and anxious personality as risk factors for eating disorder: A sister pair study. Cognitive Therapy Research, 37(4), 820-828. doi:10.1007/s10608012-9518-8

Tasca, G. A. (2014). Attachment and group psychotherapy: Introduction to a special section. Psychotherapy, 51(1), 53-56. doi:10.1037/a0033015

Tasca, G. A., \& Balfour, L. (2014a). Attachment and eating disorders: A review of current research. International Journal of Eating Disorders, 47(7), 710-717. doi:10.1002/ eat. 22302

Tasca, G. A., \& Balfour, L. (2014b). Eating disorders and attachment: A contemporary psychodynamic perspective. Psychodynamic Psychiatry, 42(2), 257-276. doi:10.1521/ pdps.2014.42.2.257

Tasca, G. A., Ritchie, K., \& Balfour, L. (2011). Implications of attachment theory and research for the assessment and treatment of eating disorders. Psychotherapy, 48(3), 249259. doi:10.1037/a0022423
Tereno, S., Soares, L., Martins, C., Celani, M., \& Sampaio, D. (2008). Attachment styles, memories of parental rearing and therapeutic bond: A study with eating disordered patients, their parents and therapists. European Eating Disorders Review, 16(1), 49-58. doi:10.1002/erv.801

Troisi, A., Di Lorenzo, G., Alcini, S., Nanni, R. C., Di Pasquale, C., \& Siracusano, A. (2006). Body dissatisfaction in women with eating disorder: Relationship to early separation anxiety and insecure attachment. Psychosomatic Medicine, 68(3), 449-453. doi:10.1097/01.psy.0000204923.09390.5b

Troisi, A., Massaroni, P., \& Cuzzolaro, M. (2005). Early separationanxietyandadultattachmentstyleinwomenwith eating disorders. British Journal of Clinical Psychology, 44(Pt 1), 89-97. doi:10.1348/014466504X20053

Valdanha, E. D., Scorsolini-Comin, F., Peres, R. S., \& Santos, M. A. (2013). Influência familiar na anorexia nervosa: Em busca das melhores evidências científicas. Jornal Brasileiro de Psiquiatria, 62(3), 225-233. doi:10.1590/ S0047-20852013000300007

Valdanha, E. D., Scorsolini-Comin, F., \& Santos, M. A. (2013). Anorexia nervosa e transmissão psíquica transgeracional. Revista Latinoamericana de Psicopatologia Fundamental, 16(1), 71-88. doi:10.1590/ S1415-47142013000100006

Grazia Attili is Emeritus Professor of the Faculty of Political Science, Sociology and Communication from the Sapienza Rome University, Rome, Italy.

Lorenza Di Pentima is a Researcher of the Faculty of Political Science, Sociology and Communication from the Sapienza Rome University, Rome, Italy.

Alessandro Toni is a Researcher of the Faculty of Political Science, Sociology and Communication from the Sapienza Rome University, Rome, Italy.

Antonio Roazzi is Full Professor at the Universidade Federal de Pernambuco, Recife-PE, Brazil.

Received: Jun. 28, 2016

1st Revision: Oct. 10, 2016

Approved: Nov. 02, 2016

How to cite this article:

Attili, G., Di Pentima, L., Toni, A., \& Roazzi, A. (2018). High anxiety attachment in eating disorders: Intergenerational transmission by mothers and fathers. Paidéia (Ribeirão Preto), 28, e2813. doi: http://dx.doi.org/10.1590/1982-4327e2813 